Conclusions The suggested approach provides consistent approach for identifying the critical CI interconnections and preparedness requirements. The benefits of the approach include the creation of common understanding of the interdependencies, establishing common concepts and introducing a systematic approach for identifying and managing the CI interconnections. The benefit of the approach for the CI service providers is the improved business continuity that is achieved by creating comprehensive understanding of the preparedness requirements.

\section{CHAIN OF RESILIENCE: AN INNOVATIVVE, EMERGING APPROACH TO AN INTERNATIONAL CONUNDRUM}

${ }^{1}$ Caroline Spencer, ${ }^{2}$ Natasia Goode, 'Dudley McArdle, 'Frank Archer. ${ }^{1}$ Monash University, Melbourne, Australia; ${ }^{2}$ University of the Sunshine Coast, Maroochydore, Australia

\subsection{6/injuryprev-2016-042156.126}

Background The global emphasis on increasing capacity in all communities to meet the growing challenge of disasters threats, be they natural, technological, environmental or manmade hazards, continues to gain momentum. Disaster resilience, now a catch-cry to reduce the effects of disaster impacts on communities commonly, depicts conceptual ambiguity. The stimulus and momentum for building disaster resilience is demonstrated in the economic losses during the period July 2013-June 2014 which saw the fourth consecutive year where disaster losses exceeded $\$ 100$ billon; 16,300 people died and 358 internationally reported disasters affected 113 million people. International and national standards and frameworks, such as the UN's Sendai Framework for Disaster Risk Reduction 2015-2030; the United Kingdom's Strategic National Framework on Community Resilience (2011); the United States' Disaster Resilience: A national imperative (2012), and the Australian National Strategy for Disaster Resilience (2011) underpin concepts to build community resilience to disasters.

Method A recent review of community and disaster resilience in peer reviewed and selected grey literature identified multiple multidisciplinary definitions.

Results No consistent definition emerged from the review. 'Resilience' presents as a cross-disciplinary, definitional conundrum for those working to build and measure disaster resilience.

Conclusion This paper offers a unique recommendation to build resilience across all sectors of society and all phases of the disaster cycle by adopting and adapting the internationally recognised, successful, community-based 'Chain of Survival' for out-of-hospital cardiac arrest as a Chain of Resilience.

Developing a community-based Chain of Resilience holds enormous potential for providing a much needed framework to create a consistent approach to building resilience across all sectors of society while maintaining conceptual flexibility for situational differences.

\section{ADAPTING HADDON'S MATRIX AS AN INNOVATIVE FRAMEWORK FOR DISASTER RISK REDUCTION AND COMMUNITY SAFETY}

Frank Archer, Caroline Spencer, Dudley McArdle. Monash University, Melbourne, Australia

10.1136/injuryprev-2016-042156.127

Background Frameworks for Disaster Health lack structure and require stronger evidence. Disaster Risk Reduction has become an international imperative, now guided by the 2015 Sendai Framework (UNISDR). Haddon's Matrix has successfully defined injury prevention countermeasures in a range of community settings over the past 30 years. This paper outlines an evolving model to underpin our understanding of Disaster Health and explores both the current and potential use of Haddon's Matrix in the setting of disaster risk reduction.

Methods A literature review was undertaken to enhance the outcomes of the WADEM Education Committee's initial 2008 framework for International Standards and Guidelines for Disaster Health Education. A second literature review examined the use of Haddon's Matrix in the disaster domain. The 2015 Sendai Framework was examined to identify elements potentially relating to Haddon's Matrix.

Results Four domains within Disaster Health were identified:

1. Comprehensive approach: the natural history of a disaster structured on the 3 phases of pre-event, event, and post event;

2. All Agency, Shared Responsibility approach: stakeholders and conceptual elements in disaster risk reduction;

3. All Hazards approach: reflecting both the traditional scope of disasters, and the contemporary scope of emergencies';

4. Generic Personal Attributes expected of the humanitarian professional.

Haddon's Matrix is rarely linked to the disaster domain, although a small number of case studies have recently reported adapting this approach to the emergency management setting. Elements identified within the 2015 Sendai Framework provide an exciting opportunity to adapt Haddon's Matrix in this setting. Conclusion Haddon's Matrix provides a framework for common communication and structuring the science and evidence-base of disaster risk reduction. It is adaptable to the contemporary concept of disaster resilience and to understanding disasters through the eyes of community safety.

\section{DISASTER PREPAREDNESS FROM THE ASPECT OF THREE HELPS (SELF-, MUTUAL- AND PUBLIC- HELP) IN JAPAN}

Yoko Shiraishi. Japan Institution for Safe Communities, Japan

\subsection{6/injuryprev-2016-042156.128}

Background Japan is a country at the high risk of natural disasters. About 20\% of the earthquakes over magnitude 6 in the world have occurred in Japan. More major earthquakes and related disasters such as tsunami and fire are also expected to hit the country in near future. Therefore, it is a very pressing issue to prepare for those emergent situations. Although governments are working for the preparation and risk management at the different levels, it is quite obvious that the public rescue would not always be available at the damaged sights right after the occurrence of disasters since public agencies could also be seriously damaged. Therefore, it is very important to make individuals and neighbourhood communities capable to rescue and survive by themselves until the public services become available. This study therefore tries to see how communities prepare for the disasters in terms of individuals (self-help) and neighbourhood community (mutual help) with the Safe Community (SC) model.

Methods The written materials such as the application reports to become a member of the international SC network, annual reports and meeting minutes of the taskforce for disaster safety 